Portland State University

PDXScholar

Curriculum and Instruction Faculty Publications

and Presentations

Curriculum and Instruction

$5-2012$

\title{
Organizational Models for Teacher Learning
}

Micki M. Caskey

Portland State University, caskeym@pdx.edu

Jan Marie Carpenter

Portland State University

Follow this and additional works at: https://pdxscholar.library.pdx.edu/ci_fac

Let us know how access to this document benefits you.

\section{Citation Details}

Caskey, M. M., \& Carpenter, J. M. (2012). Organizational models for teacher learning. Middle School Journal, 43(5), 52-62.

This Article is brought to you for free and open access. It has been accepted for inclusion in Curriculum and Instruction Faculty Publications and Presentations by an authorized administrator of PDXScholar. Please contact us if we can make this document more accessible: pdxscholar@pdx.edu. 


\section{Organizational models for teacher learning}

\section{Micki M. Caskey \& Jan Carpenter}

From the earliest reports regarding middle level education to the most recent ones, teacher learning has been central to effective middle level schools. Alexander, Williams, Compton, Hines, and Prescott (1968) asserted, "Even the most enthusiastic and well-qualified teachers must have the support of a congenial organizational framework, abundant resources, pertinent inservice programs, and appropriate evaluation procedures to assure continued optimum performance" (p. 88). In the seminal Turning Points document, the Carnegie Council on Adolescent Development (1989) highlighted how teachers working collectively can solve problems, experience professional support and less isolation, and coordinate instructional programs. In Turning Points 2000: Educating Adolescents in the 21st Century, Jackson and Davis (2000) recommended that middle level schools not only be staffed with teachers who are expert at teaching young adolescents but also engage teachers in ongoing, targeted professional development opportunities. More recently in This We Believe: Keys to Educating Young Adolescents, National Middle School Association (NMSA, now Association for Middle Level Education [AMLE], 2010) named ongoing professional development as one of its 16 tenets, explaining, "It is ... initiatives" (p. 30).

"It is important that professional development experiences provide continued participation over an extended period of time, collaborative approaches, and ongoing assessment of the effectiveness of the professional development initiatives." (p. 30)

Professional development experiences can take many forms, yet collaborative organizational models, in particular, can facilitate teachers' discussions about professional readings, student work and data, instructional practices and assessment techniques, and school improvement goals. The professionalization of teaching is dependent upon teachers having opportunities to contribute to the development of their own knowledge, engage in collegial relationships, and grow intellectually throughout the process (Holmes Group, 1986). Such collegiality among teachers can exist "when teachers work together on a shared project toward some shared goal through mutually constructed contributions" (Angelle \& Anfara, 2008, p. 52). Despite the focus on collaborative teacher learning, too many teachers, including middle grades teachers, still work in isolation and engage solely in individual professional development.

The purpose of this article is to explore organizational models for teacher learning that are being used in middle level schools, including common planning time, professional learning communities, and critical friends groups. After offering a brief definition of each model of teacher learning, we describe the theoretical underpinnings of the models, summarize the relevant research regarding the use of these models, and offer concluding remarks with implications for middle level education.

Agreeing on language regarding the organizational models that support teacher learning is a good starting point. First, common planning time is "a regularly scheduled time during the school day when teachers who teach the same students meet for joint planning, parent conferences, materials preparation, and student evaluation" (Kellough \& Kellough, 2008, p. 394). It affords interdisciplinary teams of teachersteachers from different content areas (e.g., language

This article reflects the following This We Believe characteristics: Courageous \& Collaborative Leaders, Organizational Structures, School Environment 
arts, mathematics, science, social studies) — time to collaborate. Second, professional learning communities are collaborative teams of teachers who routinely analyze their practice for the purpose of improving student achievement (DuFour, DuFour, \& Eaker, 2008). Often, they are organized in discipline-specific groups or teams. Third, critical friends groups are groups of teachers who gather regularly to consider ways to improve student learning through collaboration and inquiry. Unique to critical friends groups is the use of structured protocols. These three organizational models may be most dependent on the purpose of the teacher learning collaborative, which can be driven by internal or external forces.

\section{Theoretical underpinnings}

Lave and Wenger (1991) posited a theory_-situated learning-that contends learning is situated within authentic activity, context, and culture. Referring to the learning process as legitimate peripheral participation, they viewed learning as socially constructed. Lave and Wenger argued that legitimate peripheral participation is "a descriptor of engagement in social practice that entails learning as an integral constituent” (p. 35). In other words, individuals learn when engaged with others in activities, settings, and situations in which they would typically need and incorporate that knowledge. Essential components of situated learning theory are social interaction and collaboration through which learners participate in a community of practice.

Communities of practice are groups of people who share a common concern or a passion for something they do and learn how to do better when interacting regularly (Wenger, 1998). Communities of practice are places where knowledge exists and members of the community make sense of the knowledge within a specific context. "The purpose of the community of practice is to create knowledge based on shared goals that may increase the commitment to the community" (Angelle \& Anfara, 2008, p. 54). Key features of communities of practice include mutual engagement, joint enterprise, and shared repertoire (Wenger). Additionally, communities of practice are informal groups with flexible structures, processes, and membership, distinguishing them from formal groups that typically have fixed structures, processes, and membership. In schools, organizational models for teacher learning, which may include common planning time, professional learning communities, and critical friends groups, are usually formal groups; yet, these models remain grounded in situated learning theory and share central features with communities of practice, such as mutual engagement, joint endeavors, and shared concerns.

\section{Organizational models for teacher learning}

\section{Common planning time}

Middle level literature reveals the importance of small learning communities for teachers and students (e.g., Carnegie Council on Adolescent Development, 1989; National Association of Secondary School Principals,

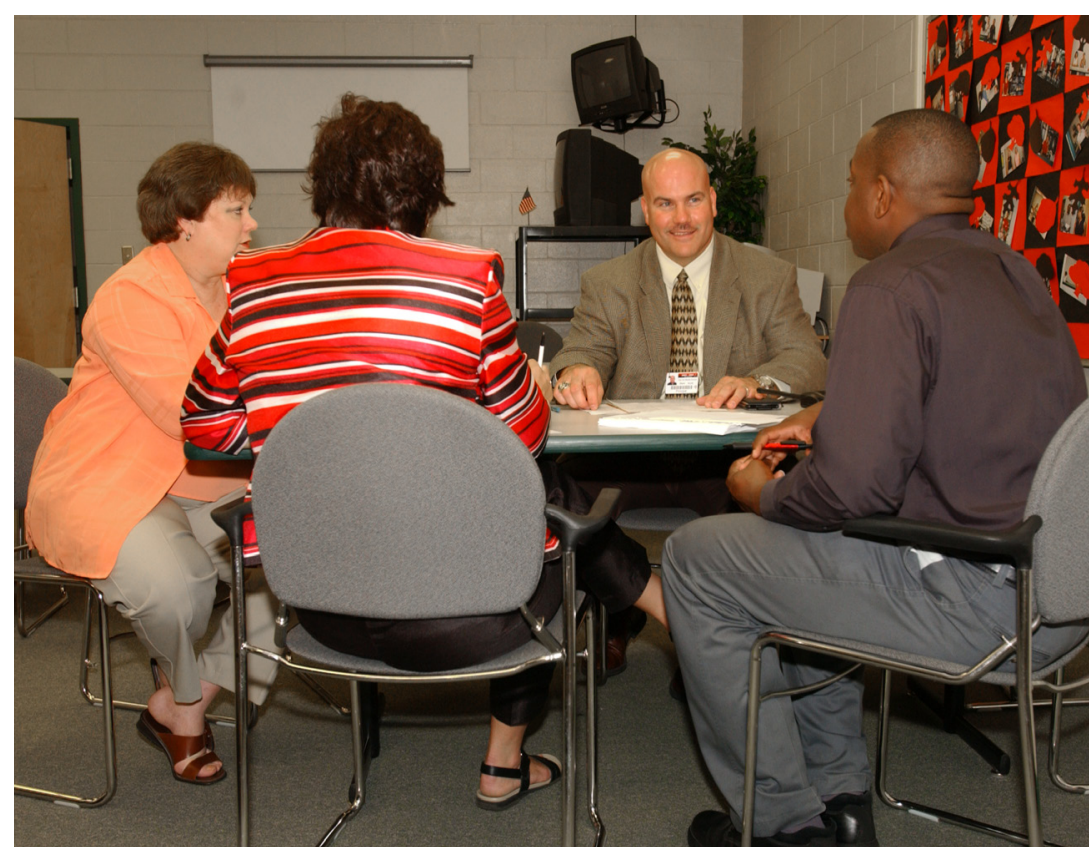

Common planning time allows a team of teachers to interact as a community of learners. photo by John Lounsbury

2006; National Forum to Accelerate Middle-Grades Reform, n.d.; NMSA, 2010). In middle level schools, these small learning communities are typically interdisciplinary teams that rely on common planning time to advance their effectiveness. The need for a common time for teachers to meet has been evident since the emergence of the middle school concept. Alexander and associates (1968) noted, "The aim of the interdisciplinary team approach is to promote communication, coordination, 
and cooperation among subject matter specialists so that students benefit from instruction planned by specialists but lacking the fragmentation [that] characterizes many departmentalized plans" (pp. 107-108).

Common planning time is "scheduled time during the day in which middle school teachers who share the same students meet to coordinate team policies and procedures, discuss students, meet with parents, plan team activities, plan thematic or cross-curricular units, look at student work, or participate in professional development" (Drolet, 2009, p. 11). In other words, it is the time for interdisciplinary teams of teachers who share the same students to meet. Because interdisciplinary teams are small learning communities within a school, they can foster professional relationships among teachers. The common planning time meeting is an ideal time for building these professional relationships. As a regular part of teachers' day, common planning time provides an opportunity for meaningful, context-specific peer interaction and professional development. It is a time reserved for teacher coordination, communication, collaboration, planning, and interaction-a time that promotes teacher learning. This shared time with professional colleagues is distinct from and in addition to teachers' individual planning time.

By definition and design, common planning time is for "joint planning, parent conferences, material preparation, and student evaluation" (Kellough \& Kellough, 2008, p. 394). It is student-centered and focuses on providing an effective, developmentally responsive education for young adolescents. The intent is to "develop plans to best meet the needs of all students" (Mis, 2008, p. 85). To this end, teachers use common planning time for specific purposes, including curriculum planning, building community, and enhancing students' overall success. With regard to curriculum planning, teachers expend time developing interdisciplinary or integrated curriculum to help students see authentic connections between school experiences and real life (Caskey, 2002). Similarly, teachers with common planning time coordinate assignments, assessments, and activities such as team events, field trips, and school-wide endeavors with students in mind (Mac Iver, 1990). Teachers also use their common planning time to build community when discussing or meeting with individual students about their overall performance or behavior; communicating or meeting with parents, teachers, and administrators; and interacting with peers including team members, counselors, and other instructional or support personnel (Drolet, 2009). Together, these uses of common planning time afford teachers occasions to evaluate students' academic and affective success and consider ways to improve both.

Researchers agree that higher levels of implementation of common planning time (i.e., a minimum of four meetings per week, with each meeting at 30 minutes or more) produce positive results for students and teachers alike (e.g., Flowers, Mertens, \& Mulhall, 1999, 2000a, 2000b; Mertens, Flowers, \& Mulhall, 1998). For students, the positive outcomes include being well known by teachers (Lipsitz, 1984) and having higher overall self-concept and positive perceptions of school climate (Warren \& Muth, 1995). Other student outcomes are reports of fewer behavior problems, lower levels of depression, higher self-esteem, and greater academic efficacy (Mertens et al., 1998) and higher levels of student achievement, especially in schools with higher percentages of free/reduced-price lunch students (Flowers et al., 1999; Mertens \& Flowers, 2003). For teachers, common planning time results in teachers

\section{Teachers' overall work life improves with high levels of common planning time.}

having positive perceptions of their working environment (Warren \& Muth, 1995) and personal teacher efficacy (Warren \& Payne, 1997). Additionally, common planning time fosters teacher collegiality (Drolet, 2009; Lipsitz, 1984; Rice, 2003) and reduces teacher isolation (Drolet, 2009; Rice, 2003). Teachers' overall work life improves with high levels of common planning time.

Beyond studies that identify the multiple, positive effects of common planning time, other research uncovers the value of common planning time as an organizational support for teacher learning. For example, Mis (2008) reported that, during this meeting time, teachers "worked together to gain new insights into situations and [to] develop solutions to problems that arose" (p. 91). In another study, Drolet (2009) found: 
Middle level teachers with high amounts of common planning time engage in best practices such as visiting each other's classrooms, observing each other's lessons and providing feedback, planning weekly team activities, collaborating weekly with the principal, sharing and reading professional articles, and completing daily and monthly team agendas. (p. 99)

Notably, teachers with common planning time seized opportunities for teacher learning through collegial endeavors such as shared professional readings and examining classroom practices. Researchers also agreed that building leadership is a critical factor in the implementation and sustained success of common planning time (Cook \& Faulkner, 2010; Drolet, 2009; Rice, 2003).

Numerous researchers have also participated in the National Middle Grades Project on Common Planning Time (Mertens, Flowers, Anfara, \& Caskey, 2010) to explore common planning time using standardized protocols. In Phase I of the project, researchers observed team meetings and interviewed teachers to explore what transpired during common planning time meetings. To date, 18 researchers have collected data from 29 schools in 13 states using these qualitative instruments. In one statewide study of Schools-to-Watch schools, Cook and Faulkner (2010) reported the importance of teachers' common vision and clearly defined goals for common planning time, whether for interdisciplinary teams, grade level teams, or professional learning communities. In another statewide study, Taylor (2009) suggested teachers would benefit from professional development about the effective and efficient use of common planning time. In a case study, Flax (2011) found "improving common planning time practice through professional development activities can enhance teacher effectiveness and, in return, student success" (p. 130).

Beginning in 2009, the National Middle Grades Project on Common Planning Time initiated a complementary quantitative study using survey constructs developed by the Center for Prevention Research and Development (Mertens, Flowers, Anfara, \& Caskey, 2011). Thus far, the data set includes more than 500 surveys from 23 schools in seven states. Preliminary results indicate that teachers with common planning time expend more time on student-related and school-wide issues than on curriculum and instructional planning, have high expectations for student achievement, and work well together (Mertens et al., 2011). Evidence from both phases of the National Middle Grades Project on Common Planning Time will provide additional information about teachers' understanding and use of common planning time, their preparation for its use, and the benefits and barriers to its implementation.

Researchers concur that common planning time has the potential to influence teacher development and school improvement. It can prompt professional growth, especially as teachers work collegially and focus on improving their teaching knowledge, skills, and practice (Rice, 2003). As Drolet (2009) asserted, "Increasing common planning time for teachers is perhaps the most important middle level reform to take place" (p. 100). Not only can common planning time foster a positive school climate (Mertens et al., 1998), it can also enhance teacher learning.

\section{Professional learning communities}

DuFour and associates (2008) defined professional learning communities as "educators committed to working collaboratively in ongoing processes of collective inquiry and action research to achieve better results for their students" (p. 14). Embedded in the contextual needs and practices of a school, professional learning communities provide a structure for continuous professional development. Professional learning communities constitute a shift from focusing on what is taught to what students learn. Student assessment data informs instructional decisions and provides evidence of teacher effectiveness (DuFour, 2004). Three assumptions undergird professional learning communities: (a) the purpose of schools is to ensure high-level learning for all students; (b) teachers cannot achieve their collective purpose in isolation; and (c) verification of effectiveness must be found in clear evidence of what students know and can do (DuFour et al., 2008).

Although the term professional learning community appeared in the 1960s, professional learning communities gained attention in the late 1980s and early 1990s (Solution Tree, n.d.). Senge's (2006) framework for learning organizations, first published in 1990, is credited as instrumental to a paradigm shift around organizational learning theory. Senge emphasized the ability of groups to expand their capacity for reaching desired results through team learning. Although Senge's work originated in the business realm, it was later applied to education. Little and McLaughlin (1993) determined 
seven elements of effective schools operating in professional learning communities: (a) shared norms and beliefs, (b) collegial relations, (c) collaborative cultures, (d) reflective practice, (e) ongoing technical inquiry regarding effective practice, (f) professional growth, and $(\mathrm{g})$ mutual support and mutual obligation. These elements remain the foundational characteristics of professional learning communities. Professional learning communities have also been associated with reform movements prompted by the release of the 1983 National Commission on Excellence in Education's report A Nation at Risk and the culture of standardization, outcomebased education, and increased accountability measures that followed (Huffman \& Hipp, 2010a).

Integrity to the professional learning community process requires collective teacher learning that leads to increased student achievement (DuFour, 2004; DuFour et al., 2008; Huffman \& Hipp, 2010a; Little \& McLaughlin, 1993; Nelson, 2009). According to DuFour and associates (2008), the collective analysis of student assessment data in relation to specific learning targets is the catalyst for teacher learning. To facilitate this process, teachers often use common formative assessments to analyze and compare student performance and evaluate teacher effectiveness (DuFour, 2004; Nelson, 2009). Teachers also use assessment data to develop instructional strategies and create systematic and timely interventions for students who need additional assistance. Experts now consider grounding teacher learning in the collective analysis of student assessment data as a key element of effective professional learning communities (Olivier \& Hipp, 2010).

Key factors in effective professional learning communities are the work and stance of the educators. Nelson (2009) explored the activities and stances of three professional learning communities and found them to have varying trajectories. One professional learning community assumed the stance of experts and invested its time in curriculum development and alignment. Another professional learning community engaged as learners of process; the members moved methodically through each step, exploring their values and beliefs about educational practice and determining how to develop data collection tools, analyze data, and implement other aspects of the inquiry cycle. A third professional learning community in Nelson's study immersed itself as learners in the examination of student work. As they participated in the process, they experienced deep learning about students, teaching, learning, and themselves. Despite the adoption of professional learning communities as an organizational model, transforming the culture of a school has remained a complex and challenging task (DuFour et al., 2008; Hipp, Huffman, Pankake, \& Olivier, 2008; Nelson).

Educators reported benefits to working in various types of professional learning communities. Teams that invested in collaborative planning (a) felt connected to and supported by their colleagues, (b) became more efficient at curriculum planning, (c) credited professional learning communities with assisting individuals to implement mandated curriculum reform, and (d) expressed enhanced resilience (Dallas, 2006). Nelson (2009) found that professional learning communities that shared expert knowledge gained ideas and examined beliefs in ways uncommon in most schools. Nevertheless, an inquiry stance was the essential element of transformational learning-learning that changed classroom practice. Such an inquiry stance required a willingness to question, to hold uncomfortable tensions, to be vulnerable with colleagues, to struggle, to challenge the status quo, and to pose problems (Cochran-Smith \& Lytle, 1992; DuFour et al., 2008; Nelson; Nelson \& Slavit, 2008; Senge et al., 2000). In Nelson's study, the professional learning community that experienced transformed practice explored patterns, asked complex questions, challenged each other's views, examined its own assumptions, developed strategies, and analyzed student growth over time.

Bloom and Vitcov (2010) distinguished between doing the work of a professional learning community and being a professional learning community; doing implies compliance with mandates and/or occasional activity, while being involves embracing and enacting the concepts as part of everyday practice. Researchers reported that moving from doing to being is a learning process that develops over time (DuFour et al., 2008; Schechter, 2010; Slavit, Kennedy, Nelson, \& Deuel, 2011). In a five-year case study, Slavit and associates (2011) found systemic change followed a trajectory: (a) teachers learned to talk to each other, (b) teachers individually used data to inform practice, (c) teachers collectively used data to inform practice, and (d) teachers took seriously the responsibility to reach all learners. Schechter also identified dynamic and interrelated stages of learning, including invitation and framework building, collective inquiry, and experimentation and dissemination. Emotions shifted throughout the process; participants expressed skepticism, suspicion, or intrigue and 
enthusiasm at first, then expressed reluctance to share experiences and successes, and, finally, transitioned to feeling encouraged, supported, and interconnected.

Olivier, Hipp, and Huffman (2003) framed the development of professional learning communities into four dimensions: not initiating, initiating, implementing, sustaining. Huffman and Hipp (2010a) encouraged schools to assess their progress with these dimensions to determine evidence of effectiveness and to set goals. Their assessment measured: (a) shared and supportive leadership, (b) shared values and vision, (c) collective learning and application, (d) shared personal practice, (e) supportive structures, and (f) supportive relationships. Huffman and Hipp also evaluated external support systems, including the involvement of the central office, involvement of parents and families, and support of the community.

Slavit and associates (2011) listed forces that enabled reform to occur over time. Teachers participated in "needs-focused professional development" (p. 118), which focused on general needs identified by participants. Guided instruction and practice with the collaborative learning process allowed teachers to learn experientially. After learning to use data to inform their practice, teachers identified and received professional development on specific contextual needs related to gaps in their professional knowledge and skill. While teachers began with broad conversations about beliefs and activities that were focused on how to $d o$ professional learning community work, they shifted to being a professional learning community through their commitment to and investment in the process.

Researchers have also examined elements of sustainable professional learning communities (Hipp et al., 2008; Nelson, 2009). Hipp and associates (2008) identified a strong shared vision for and commitment to student learning; teachers in highly effective professional learning communities were "impassioned with a common cause" (p. 180). In other words, they exhibited an undeviating and active commitment to student learning. Nelson (2009) connected sustainability to a culture of collegiality versus settling for a culture of congeniality. She noted that teachers in congenial school cultures protect privacy and acknowledge differing philosophical and pedagogical beliefs yet rarely engage in dialogue that explores their differences. Conversely, collegial cultures are characterized by the intentional development of trust, willingness to take risks, and a collective confidence that facilitates conversations about challenging the status quo. In collegial cultures, teachers are able to assume an intellectual rather than emotional approach to conflict and to work through uncomfortable and awkward feelings that accompany learning new ways of being. Structured protocols are instrumental in the facilitation of the process (Hipp et al., 2008; Nelson, 2009) as are multiple opportunities for collaborative inquiry, such as critical friends groups, peer coaching, and common planning time (Hipp et al., 2008). Hipp and associates credited teamwork and shared responsibility for the ability to implement and sustain change.

\section{Visionary leaders foster a culture of collaboration and provide the necessary supports for professional learning communities to be successful.}

A culture of learning requires supportive and shared leadership (DuFour et al., 2008; Huffman \& Hipp, 2010a; Little \& McLaughlin, 1993). Educators in effective professional learning communities acknowledge their leaders for setting the tone and direction for the school climate (Hipp et al., 2008). Visionary leaders foster a culture of collaboration and provide the necessary supports for professional learning communities to be successful.

DuFour and associates (2008) asserted, "The most promising strategy for sustained, substantive school improvement is developing the ability of school personnel to function as a professional learning community" (p. 1). However, they emphasized that it involves a developmental process. Bringing a group of teachers together and asking them to work on a task does not make them a collaborative team. Commitment to an idea is different from knowing how to implement change (Joyce, 2004). Team learning is a skill that requires commitment, knowledge, and practice for it to be sustained. Effective professional learning communities are dependent on practices being embedded into the culture of a school rather than being viewed as "shortterm or quick fixes to perceived problems" (Huffman \& Hipp, 2010b, p. 25). If they are so perceived, the impact will be superficial, confined to a few participants, and 
generally ineffective. However, teachers who experience professional learning communities as the "container that holds the culture" (Hipp et al., 2008, p. 192) feel invigorated, challenged, professionally engaged, and empowered.

\section{Critical friends groups}

A critical friends group is a professional learning community of approximately $8-12$ educators who come together voluntarily to improve their practice through collaborative learning (National School Reform Faculty, n.d.). Typically, groups meet at least once a month for about two hours. According to Bambino (2002), "Critical friends groups help people involved with schools to work collaboratively in democratic, reflective communities" (p. 25). The groups use collaborative processes that acknowledge the complexity of teaching and learning. A rather new organizational model for professional development, critical friends groups bring together practitioners and foster teacher learning.

The idea for critical friends groups is relatively recent. In 1994, 12 expert educators associated with the Coalition of Essential Schools and the Annenberg Institute for School Reform met to develop a new model for professional development. These specialists were dissatisfied with traditional professional development approaches such as scripted workshops and motivational presentations (Dunne, Nave, \& Lewis, 2000) and wanted to design a different approach-one focused on the practitioner and on the improvement of student learning (National School Reform Faculty, n.d.). They grounded their design of the critical friends group model in research (see McLaughlin \& Talbert, 1993; Newmann, 1994). The newly envisioned program was to be practitioner-driven, school environment-specific, and collaborative. Additional features of this unique model for professional development included coaches and specific protocols to guide practitioners as they engaged in collaborative teacher learning. Training programs for critical friends groups began in 1995 with 88 coaches in 70 schools and grew to more than 1,000 coaches in 700 schools by the end of the decade (Dunne et al., 2000). Since that time, the National School Reform Faculty has continued to coordinate training and support for coaches and critical friends groups.

Purposes of critical friends groups are multifaceted and include (a) identifying school-specific student learning goals, (b) reflecting on practices for achieving student learning goals, and (c) collaboratively examining teacher and student work to meet the student learning goals (Dunne et al., 2000). To create a community of learners in which teaching and learning improve, members of critical friends groups need to make their teaching practice explicit and public by talking about teaching. In the spirit of inquiry, members guide one another to translate theory and research into teacher and student learning. Critical friends groups also require a context in which members can examine their work with students, engage in collegial relationships with peers, and consider their own assumptions and beliefs about teaching and learning.

\section{Ultimately, teacher learning is not determined by whether a school has an organizational model but by how educators engage within the organization model.}

Critical friends groups, as learning communities, are strongest when teachers in the school demonstrate (a) reflective dialogue, (b) deprivatization of practice, (c) collective focus on student learning, (d) collaboration, and (d) shared norms and values (Kruse, Seashore Lewis, $\&$ Bryk, 1994). To flourish, these learning communities require structural conditions including time to meet, places to meet, interdependent roles, opportunities to exchange ideas, and a sense of empowerment and autonomy. Similarly, these learning communities develop best with conditions such as openness to improvement, trust and respect, expertise regarding the knowledge and skills of teaching, supportive leadership, and socialization to transmit the school's vision (Kruse et al., 1994).

To facilitate the collaborative process, coaches and members of the critical friends groups use standard protocols. According to Norman, Golian, and Hooker (2005), coaches use protocols to create conditions for a professional learning community. The protocols help to structure professional talk and "to create focused, substantive, equitable dialogue” (Norman et al., p. 285). The protocols, which are varied and depend on the particular goals of the critical friends group, include 
Affinity Mapping, and Chalk Talk to Save the Last Word for Me and Zones of Comfort, Risk and Danger: Constructing Your Zone Map. They are all posted on the National School Reform Faculty website, but while the protocols are freely available, a notation reminds users, "Protocols are most powerful and effective when used within an ongoing professional learning community, such as a critical friends group, and facilitated by a skilled coach" (National School Reform Faculty, n.d.). The National School Reform Faculty website also provides information about training and support for coaches and critical friends groups. Skilled coaches and guiding protocols are distinctive characteristics of critical friends groups intended to facilitate ongoing teacher learning.

Evaluation of critical friends groups started in 1995 when the Annenberg Institute commissioned a two-year study of the effectiveness of this professional development approach (Dunne et al., 2000), which included survey measures as well as observations and interviews. Comparisons of survey responses of critical friends groups and non-critical friends groups teachers showed statistically significant differences for all measured components: (a) opportunities to learn new things from peers, (b) professional engagement with peers, (c) collaboration with peers, (d) adaptation of instruction, (e) expectations of students, (f) support by administration, (g) district influence on practice, and (h) state influence on practice. Members of critical friends groups reported reasons their work was more satisfying than traditional professional developmentit is continual, focuses on their own teaching and their own students' learning, and takes place in small-group settings with trusted, supportive colleagues in their own schools (Dunne et al., 2000). Overall findings indicated that skilled coaches were essential, and critical friends groups that spent the majority of meeting time analyzing student or teacher work samples experienced the most change in teachers' thinking and practice (Dunne et al.). In sum, critical friends groups influenced teacher learning.

Since the initial evaluation of critical friends groups, researchers have continued to examine the effect of critical friends groups (Curry, 2008; Key, 2006; Norman et al., 2005). For instance, Norman and associates (2005) explored the participation of a teacher candidate, a mentor teacher, and a university faculty member in a critical friends group at an elementary-level professional development school. They described how these educators used different protocols to engage with one another; noted the power of the protocols to create "focused, substantive, equitable dialogue;" and concluded that participation in critical friends groups promotes "an inquiry-oriented, practice-based, self-disclosing form of conversation" (Norman et al., p. 285). In another study, Curry (2008) examined how critical friends groups at the high school level function as resources for instructional improvement and school reform. After exploring design features including (a) diverse menu of activities, (b) decentralized structure, (c) interdisciplinary membership, and (d) protocol reliance, Curry documented the possibilities and limitations of these features to advance instructional improvement and school reform. She reported that critical friends groups enhanced teachers' collegial relationships, awareness of research-based practices, school-wide knowledge, and capacity for instructional improvement, but they had little effect on teachers' pedagogical content knowledge. In a review of research, Key (2006) analyzed 16 studies regarding the efficacy of critical friends groups for professional development and school reform. While she found substantive evidence that critical friends groups foster a culture of community and collaboration and enhance teacher professionalism, Key noted less definitive support that critical friends groups have the potential to change teachers' thinking and practice and to impact student learning.

Other researchers have considered how critical friends groups function over time (Burke, Marx, \& Berry, 2011; Hipp et al., 2008). In a five-year case study of critical friends groups, Hipp and associates (2008) examined learning community cultures at two schools-a K-8 and a middle school. The K- 8 school used critical friends groups as well as other embedded professional development structures, such as peercoaching and common planning time, to target all students. In addition to a school-wide focus on learning and curriculum, Hipp and associates found teachers in critical friends groups discussed student work and resolved school and classroom issues in cross-grade and subject area teams.

Critical friends is credited widely for the dramatic change in the way teachers come together as a faculty to learn through sharing and feedback. Teachers across primary and MS [middle school grades] get together in mixed groups once a month and bring critical issues/classroom dilemmas and student work to their groups of 12-14. (p. 183) 
Teachers noted how critical friends groups helped to build relationships and foster trust so that they viewed one another as valuable resources. In the third year of a longitudinal study, Burke and associates (2011) evaluated a district's use of critical friends groups and provided district leaders with feedback to inform implementation. Findings indicated that the degree of integration of critical friends groups with other school improvement initiatives influenced how individuals conceptualized their roles in improving instruction (teachers) and achievement (students). Burke and associates found that critical friends groups replaced traditional forms of professional development, and participants exhibited high levels of support and commitment for critical friends groups as a professional development model. They concluded that attainment of improved student achievement "will require an intensive and long-term commitment to a complex developmental CFT [critical friends groups'] implementation process" (p. 49). When critical friend groups are developed and sustained, the results may include teacher learning and improved student learning.

\section{Concluding remarks}

Common planning time, professional learning communities, and critical friends groups are organizational models designed to facilitate teacher learning that ultimately benefits students. The contextspecific focus of each model allows educators to create professional knowledge grounded in the needs of their practice. The potential for teacher engagement and professional development is high for each of these models, and the collaborative relationships they foster are a significant departure from the traditional role of teachers working in isolation. Critical factors for reculturing schools to embody collaborative relationships and teacher learning include the following: strong and supportive leadership, a shared vision, an inquiry stance, trust, and willingness to be transparent about practice. Ultimately, teacher learning is not determined by whether a school has an organizational model but by how educators engage within the organization model. This warrants consideration of several implications related to how to engage educators effectively.

\section{Implications}

Time. Teachers need time-regular, sufficient, and dedicated time for teacher collaboration within the school schedule-for teacher learning to result in sustained, substantive school improvement. Given the current conditions in the U.S. education system, time may be difficult to secure for this purpose. Nevertheless, if the goal is improved student learning and achievement, teachers must have time to collaborate. Wei, DarlingHammond, Andree, Richardson, and Orphanos (2009) reported that most schools in European and Asian countries dedicate 15-20 hours per week to the planning, assessment, and activities that support the act of teaching, and most of these activities are accomplished in collegial teams of various configurations. In contrast, U.S. schools typically provide teachers with three to five hours per week for planning and related responsibilities, and teachers often work in isolation during this time. To support their educational reform efforts, policymakers must consider the growing body of evidence about the positive effect increased teacher professional time has on student learning gains.

Teacher education. Teachers need opportunities to learn about organizational models for teacher learning. For the models to be effective and lead to improved student learning, teachers must know the model's intended purpose(s) and know how to use the model in their school's context. Teachers need ongoing professional development and support to participate actively and collaboratively with their peers. They also require instructional coaching or other forms of school-based instruction to guide and deepen their understanding of the model or models. In the same way, preservice teacher candidates need instruction about organizational models to advance teacher learning throughout their teacher preparation programs. Teacher candidates not only need instruction about various organizational models, they also deserve opportunities to discuss the importance of continual professional growth, engage with their peers in collaborative learning, and participate in models of teacher learning during their clinical experiences. Investing in teacher education at both the inservice and preservice levels can prompt and sustain teacher learning. 


\section{Extensions}

Talk with educators in your school about organization models for teacher learning. What models are available in your school? Consider what teachers could do collectively to take greater advantage of the model(s). Identify supports teachers need to enhance the effectiveness of teacher learning in your school. Exchange ideas about actions and supports related to teacher learning with peers and school leaders.

Initiate an assessment of the organizational models for teacher learning used in your school. What assessment tools would be useful to guide an assessment? Conduct an assessment and examine the results to determine how the organizational model functions in your school. How can schools use time and teacher education to advance the effectiveness of the model?

\section{References}

Alexander, W. M., Williams, E. L., Compton, M., Hines, V. A., \& Prescott, D. (1968). The emergent middle school. New York, NY: Holt, Rinehart, \& Winston.

Angelle, P., \& Anfara, V. A., Jr. (2008). Communities of practice. Middle School Journal, 39(5), 52-58.

Bambino, D. (2002). Critical friends. Educational Leadership, 59(6), 25-27.

Bloom G., \& Vitcov, B. (2010). PLCs: A cultural habit built on trust. Leadership, 39(4), 24-26.

Burke, W., Marx, G. E., \& Berry, J. E. (2011). Maintaining, reframing, and disrupting traditional expectations and outcomes for professional development with critical friends groups. The Teacher Educator, 46, 32-52.

Carnegie Council on Adolescent Development. (1989). Turning points: Preparing American youth for the 21st century. New York, NY: Carnegie Corporation.

Caskey, M. M. (2002). Authentic curriculum: Strengthening middle level education. In V. A. Anfara, Jr. \& S. L. Stacki (Eds.), Middle school curriculum, instruction, and assessment (pp. 103-117). Greenwich, CT: Information Age.

Cochran-Smith, M., \& Lytle, S. L. (1992). Communities for teacher research: Fringe or forefront? American Journal of Education, 100(3), 298-324.

Cook, C. M., \& Faulkner, S. A. (2010). The use of common planning time: A case study of two Kentucky Schools to Watch. Research in Middle Level Education Online, 34(2), 1-12.

Curry, M. W. (2008). Critical friends groups: The possibilities and limitations embedded in teacher professional communities aimed at instructional improvement and school reform. Teachers College Record, 110(4), 733-774.

Dallas, F. (2006). Enhancing the 3r's of resilience, retention, and reform through middle school faculty professional learning communities. Middle Grades Research Journal, 1(1), 67-92.

Drolet, R. (2009). Meeting increased common planning time requirements: A case study of middle schools in three Rhode Island districts. (Doctoral dissertation). Retrieved from Dissertations \& Theses: Full Text. (Publication No. AAT 3350094).

DuFour, R. (2004). What is a professional learning community? Educational Leadership, 61(8), 6-11.

DuFour, R., DuFour, R., \& Eaker, R. (2008). Revisiting professional learning communities at work. Bloomington, IN: Solution Tree.
Dunne, F., Nave, B., \& Lewis, A. (2000). Critical friends groups: Teachers helping teachers to improve student learning. Phi Delta Kappa International Research Bulletin (CEDR) (28). Retrieved from http://www.pdkintl.org/research/rbulletins/resbul28.htm

Flax, K. (2011). Common plan time at the middle school level. (Doctoral dissertation). Retrieved from Dissertations \& Theses: Full Text. (Publication No. AAT 3456138).

Flowers, N., Mertens, S. B., \& Mulhall, P. (1999). The impact of teaming: Five research-based outcomes of teaming. Middle School Journal, 31(2), 57-60.

Flowers, N., Mertens, S. B., \& Mulhall, P. (2000a). What makes interdisciplinary teams effective? Middle School Journal, 31(4), $53-56$.

Flowers, N., Mertens, S. B., \& Mulhall, P. (2000b). How teaming influences classroom practices. Middle School Journal, 32(2), $52-59$.

Hipp, K. K., Huffman, J. B., Pankake, A. M., \& Olivier, D. F. (2008). Sustaining professional learning communities: Case studies. Journal of Educational Change, 9, 173-195.

Holmes Group. (1986). Tomorrow's teachers: A report of the Holmes Group. East Lansing, MI: Author.

Huffman, J. B., \& Hipp, K. K. (2010a). Introduction. In K. K. Hipp \& J. B. Huffman (Eds.), Demystifying professional learning communities: School leadership at its best (pp. 1-9). Lanham, MD: Rowman \& Littlefield Education.

Huffman, J. B., \& Hipp, K. K. (2010b). Methodology and conceptual framework. In K. K. Hipp \& J. B. Huffman (Eds.), Demystifying professional learning communities: School leadership at its best (pp. 23-28). Lanham, MD: Rowman \& Littlefield Education.

Jackson, A. W., \& Davis, G. A. (2000). Turning points 2000: Educating adolescents in the 21st century. New York, NY \& Westerville, OH: Teachers College Press \& National Middle School Association.

Joyce, B. (2004). How are professional learning communities created? History has a few messages. Phi Delta Kappan, 86(1), $76-83$.

Kellough, R. D., \& Kellough, N. G. (2008). Teaching young adolescents: Methods and resources for middle grades teaching (5th ed.). Upper Saddle River, NJ: Pearson Merrill Prentice Hall.

Key, E. (2006, January). Do they make a difference? A review of research on the impact of Critical Friends Groups. Paper presented at the National School Reform Faculty Research Forum, Denver, CO.

Kruse, S., Seashore Lewis, K., \& Bryk, A. (1994). Building professional community in schools. Issues in Restructuring Schools, 6, 2-6. Madison, WI: Center on Organization and Restructuring of Schools. Retrieved from http://www.wcer.wisc. edu/archive/cors/issues_in_restructuring_schools/issues_ no_6_spring_1994.pdf

Lave, J., \& Wenger, E. (1991). Situated learning: Legitimate peripheral participation. New York, NY: Cambridge University Press.

Lipsitz, J. (1984). Successful schools for young adolescents. New Brunswick, NJ: Transaction.

Little, J. W., \& McLaughlin, M.W. (Eds.). (1993). Teachers' work: Individuals, colleagues, and contexts. New York, NY: Teachers College Press.

Mac Iver, D. J. (1990). Meeting the needs of young adolescents: Advisory groups, interdisciplinary teaching teams, and school transition programs. Phi Delta Kappan, 71(6), 458-464.

McLaughlin, M. W., \& Talbert, J. E. (1993). Contexts that matter for teaching and learning: Strategic opportunities for meeting the nation's educational goals. Palo Alto, CA: Center for Research on the Context of Secondary School Teaching. Retrieved from http:// www.eric.ed.gov/PDFS/ED357023.pdf 
Mertens, S. B., \& Flowers, N. (2003). Middle school practices improve student achievement in high poverty schools. Middle School Journal, 35(1), 33-43.

Mertens, S. B., Flowers, N., \& Mulhall, P. (1998). The Middle Start Initiative, Phase I: A longitudinal analysis of Michigan middle-level schools. Center for Prevention Research and Development, University of Illinois.

Mertens, S. B., Flowers, N., Anfara, V. A., Jr., \& Caskey, M. M. (2010). Common planning time. Middle School Journal, 41(5), $50-57$.

Mertens, S. B., Flowers, N., Anfara, V. A., Jr., \& Caskey, M. M. (2011, November). What research says... The National Project on Middle Level Common Planning Time. Session presented at the annual meeting of the Association for Middle Level Education, Louisville, KY.

Mis, R. (2008). An examination of how middle school teachers use common planning time to foster their professional learning. (Doctoral dissertation). Retrieved from Dissertations \& Theses: Full Text. (Publication No. AAT 3327131).

National Association of Secondary School Principals. (2006). Breaking ranks in the middle: Strategies for leading middle level reform. Reston, VA: Author.

National Forum to Accelerate Middle-Grades Reform. (n.d.). Vision statement. Retrieved from: http://www.mgforum.org/ AbouttheForum/OurVisionStatement/tabid/99/Default.aspx

National Middle School Association. (2010). This we believe: Keys to educating young adolescents. Westerville, $\mathrm{OH}$ : Author.

National School Reform Faculty. (n.d.). What is a CFG? Retrieved from http://www.nsrfharmony.org/

Nelson, T. H. (2009). Teachers' collaborative inquiry and professional growth: Should we be optimistic? Science Education, $93,548-580$.

Nelson, T., \& Slavit, D. (2008). Supported teacher collaborative action. Teacher Education Quarterly, 35(1), 99-116.

Newmann, F. M. (1994). School-wide professional community. Issues in Restructuring Schools, 6, 1-2. Madison, WI: Center on Organization and Restructuring of Schools. Retrieved from http://www.wcer.wisc.edu/archive/cors/issues_in_ restructuring_schools/issues_no_6_spring_1994.pdf

Norman, P. J., Golian, K., \& Hooker, H. (2005). Professional development schools and critical friends groups: Supporting student, novice, and teacher learning. The New Educator, 1, 273-286.
Olivier, D. F., \& Hipp, K. K. (2011). Assessing and analyzing schools as professional learning communities. In K. K. Hipp \& J. B. Huffman (Eds.), Demystifying professional learning communities: School leadership at its best (pp. 29-41). Lanham, MD: Rowman \& Littlefield Education.

Olivier, D. F., Hipp, K. K., \& Huffman, J. B. (2003). Assessing schools as PLCS. In J. B. Huffman \& K. K. Hipp (Eds.), Reculturing schools as professional learning communities (pp. 67-74). Lanham, MD: Scarecrow Press.

Rice, J. M. (2003). How common planning time affects collegiality: A case study. (Doctoral dissertation). Retrieved from Dissertations \& Theses: Full Text. (Publication No. AAT 3103233).

Schechter, C. (2010). Learning from success as leverage for a professional learning community: Exploring an alternative perspective of school improvement process. Teachers College Record, 112(1), 182-224.

Senge, P. M. (2006). The fifth discipline: The art and practice of the learning organization. New York, NY: Doubleday.

Senge, P., Cambron-McCabe, N., Lucas, T., Smith, B., Dutton, J., \& Kleiner, A. (2000). Schools that learn: A fifth discipline fieldbook for educators, parents, and everyone who cares about education. New York, NY: Doubleday.

Solution Tree. (n.d.). All things PLC. Retrieved from http://www.allthingsplc.info/

Slavit, D., Kennedy, A., Nelson, T. H., \& Deuel, A. (2011). Support for professional collaboration in middle school mathematics: A complex web. Teacher Education Quarterly, 38(3), 113-131.

Taylor, M. J. (2009, April). Middle grade interdisciplinary team planning in the context of No Child Left Behind. Paper presented at the annual meeting of the American Educational Research Association, San Diego, CA.

Warren, L., \& Muth, K. (1995). The impact of common planning time on middle grade students and teachers. Research in Middle Level Education Quarterly, 18(3), 41-58.

Warren, L., \& Payne, B. (1997). Impact of middle grades' organization on teacher efficacy and environmental perceptions. Journal of Educational Research, 90(5), 1-13.

Wei, R. C., Darling-Hammond, L., Andree, A., Richardson, N., \& Orphanos, S. (2009). Professional learning in the learning profession: A status report on teacher development in the United States and abroad. Dallas, TX. National Staff Development Council.

Wenger, E. (1998). Communities of practice: Learning, meaning, and identity. New York, NY: Cambridge University Press.

Micki M. Caskey is professor of middle grades education in the Department of Curriculum and Instruction at Portland State University. She is the chair for the Association of Middle Level Education's Research Advisory Committee; past editor of Research in Middle Level Education Online; and immediate past chair of the Middle Level Education Research Special Interest Group, an affiliate of the American Educational Research Association. E-mail: caskeym@pdx.edu

Jan Carpenter is an assistant professor in the Department of Teaching and director of the full-time Master's of Teaching program at George Fox University. She is chair of the Association for Middle Level Education's Professional Preparation Advisory Committee and chair of the Oregon Middle Level Consortium. E-mail: jcarpenter@georgefox.edu 